\section{IMPLANTABLE CARDIOVERTER- DEFIBRILLATOR}

\section{Evaluation of clinical neurologic outcome and electroencephalographic changes during implantation}

During placement of implantable cardioverter-defibrillators, ventricular arrhythmias are induced to test the function of the devices. Although cerebral hypoperfusion and ischemic electroencephalographic changes occur in patients while implantable cardioverter-defibrillators are being tested, no investigation has assessed neurologic outcome in these patients. Nine patients having either implantation or change of an implantable cardioverter-defibrillator underwent neurologic examination and neuropsychometric tests before and after the operation. After induction of general anesthesia and insertion of implantable cardioverter-defibrillator leads (when needed), ventricular fibrillation, ventricular flutter, or ventricular tachycardia, was induced by means of programmed electrical stimulation. Implantable cardioverterdefibrillator testing continued until satisfactory lead placement was confirmed. The intraoperative electroencephalographic recording was analyzed for evidence of ischemic change. In all, an electroencephalogram was recorded during 50 periods of circulatory arrest. Mean duration of the arrest periods was 13.6 seconds. By means of conventional visual inspection of the raw electroencephalogram, high-amplitude rhythmic delta or theta, voltage attenuation, or loss of fast frequency activity was observed in 30 of the arrests. By means of an automated technique of electroencephalographic interpretation based on power spectral analysis, electroencephalographic changes were correctly identified in 26 of the arrests. The incidence of these electroencephalographic changes was dependent on the arrest duration. The mean interval from arrest onset to electroencephalographic change was 7.5 seconds (standard deviation \pm 1.8 seconds). In patients with electroencephalographic changes during multiple arrests, no downward trend in this interval was detected in later arrests and no evidence of persistent ischemic change was observed in electroencephalograms recorded after the conclusion of implantable cardioverterdefibrillator testing. Postoperative neurologic and neuropsychometric testing was completed in eight patients, none of whom exhibited a new neurologic deficit, exacerbation of a preexisting neurologic condition, or significant deterioration in neuropsychometric performance. We conclude that the brief arrest of cerebral circulation induced during insertion of an implantable cardioverter-defibrillator is not associated with permanent neurologic injury. (J THORAC CARDIOvaSC SURG 1995;109:565-73)

David C. Adams, MD, ${ }^{a}$ Eric J. Heyer, MD, PhD, ${ }^{\mathrm{a}, \mathrm{b}}$ Ronald G. Emerson, MD, Henry M. Spotnitz, MD, Ellise Delphin, MD, ${ }^{\mathrm{a}}$ Christine Turner, BS, ${ }^{\mathrm{b}}$ and Mitchell F. Berman, MD, ${ }^{\mathrm{a}}$ New York, N.Y.
Implantable cardioverter-defibrillators (ICDs) terminate malignant ventricular tachyarrhythmias and are therefore effective in the prevention of sudden cardiac death from ventricular tachycardia (VT), ventricular flutter (VFL), or ventricular fibrillation (VF). During implantation of ICDs, cerebral hypoperfusion occurs when these arrhythmias are induced to establish defibrillator lead placement and verify their functioning. The clinical significance of electroencephalographic (EEG) changes that accompany this hypoperfusion ${ }^{1-5}$ has yet to be determined. Repeated episodes of transient cerebral hy- poperfusion are associated with histologic evidence of neuronal injury in animals, ${ }^{6-9}$ and a cumulative EEG effect has been described in patients having more than six VF arrests during ICD placement ${ }^{4}$; however, the neurologic sequelae of brief, repeated episodes of normothermic circulatory arrest in human beings have not been determined. In this study, patients undergoing ICD implantation were examined for clinical evidence of cerebral dysfunction as determined by neurologic examination, a neuropsychometric battery, and the EEG. 
Table I. Patient age, diagnosis, number of induced circulatory arrests, range and average of arrest durations, arrests showing EEG change, and false positive and negative events

\begin{tabular}{|c|c|c|c|c|c|c|c|c|c|}
\hline $\begin{array}{c}\text { Patient } \\
\text { No. }\end{array}$ & $\begin{array}{l}\text { Age } \\
(y r)\end{array}$ & $\operatorname{Sex}$ & $D x$ & $\begin{array}{c}\text { No. of } \\
\text { CA }\end{array}$ & $\begin{array}{c}\text { Mean } C A \\
\text { duration } \\
(\mathrm{sec})\end{array}$ & $\begin{array}{l}\text { Range } \overline{C A A} \\
\text { duration } \\
\text { (sec) }\end{array}$ & $\begin{array}{l}C A \text { with raw } \\
E E G \text { change }\end{array}$ & $\begin{array}{c}C A \text { with } \\
\text { processed } \\
\text { EEG change }\end{array}$ & $\begin{array}{l}\text { False } \\
\text { events }\end{array}$ \\
\hline 1 & 25 & F & TOF & 18 & 13.8 & $6.8-25.6$ & $12 / 18$ & $13 / 18$ & $4 \mathrm{FN}, 1 \mathrm{FP}$ \\
\hline 2 & 40 & $\mathrm{~F}$ & SAR & 6 & 11.9 & $5.4-23.2$ & $1 / 6$ & $3 / 6$ & $2 \mathrm{FP}$ \\
\hline 3 & 40 & $\mathrm{M}$ & $\mathrm{CAD}$ & 4 & 9.9 & $6.0-19.7$ & $1 / 4$ & $2 / 4$ & $1 \mathrm{FP}$ \\
\hline $4^{*}$ & 69 & $\mathbf{M}$ & CAD & 1 & 17.4 & 17.4 & $1 / 1$ & $1 / 1$ & \\
\hline 5 & 65 & $\mathrm{~F}$ & CAAD & 3 & 11.7 & $9.8-14.4$ & $1 / 3$ & $1 / 3$ & \\
\hline 6 & 44 & $\mathrm{M}$ & $\mathrm{CAD}$ & 3 & 11.9 & $7.6-19.8$ & $2 / 3$ & $3 / 3$ & $1 \mathrm{FP}$ \\
\hline 7 & 22 & $\mathrm{M}$ & TOF & 10 & 21.2 & $14.2-31.2$ & $10 / 10$ & $10 / 10$ & \\
\hline 8 & 51 & $\mathrm{M}$ & TOF & 2 & 10.8 & $6.4-15.2$ & $1 / 2$ & $2 / 2$ & $1 \mathrm{FP}$ \\
\hline 9 & 60 & $\mathbf{F}$ & $\mathrm{CAD}$ & 3 & 10.3 & $8.6-13.6$ & $1 / 3$ & $1 / 3$ & \\
\hline
\end{tabular}

$D x$, Diagnosis; $T O F$, tetralogy of Fallot; $S A R$, sarcoidosis; $C A D$, coronary artery disease; $C A$, circulatory arrest (VF or pulseless VFL); False events, false processed EEG interpretations as compared with visual interpretation of the raw EEG; $F N$, false negative; $F P$, false positive.

${ }^{*}$ Patient 4 had ICD generator change.

\section{Patients and methods}

After receiving approval from our institutional review board and obtaining written informed consent, we studied eight patients who were to undergo implantation of an ICD (Cardiac Pacemakers, Inc., St. Paul, Minn.) and one patient who was to undergo ICD generator change (Table I). Average age of the patients was 47 years (range 22 to 69 years). Clinical outcome was assessed by comparing preoperative with postoperative neurologic examinations and neuropsychometric test scores. All examinations were performed by a board-certified neurologist (E.J.H.). Eight standard neuropsychometric tests were used: HalsteadReitan Trails $\mathbf{A}$ and $\mathbf{B},{ }^{10}$ finger tapping test, ${ }^{11}$ and grooved pegboard ${ }^{12}$ with dominant and nondominant hands, Buschke Selective Reminding Test, ${ }^{13}$ and a quantitative Mini-Mental Status Test. ${ }^{14}$ These tests were selected for their reliability, ease of administration, patient acceptance, and ability to demonstrate general neuropsychologic abilities, including memory, attention, orientation, language, and motor functioning. The neuropsychometric data were analyzed by group rate and event rate comparison methods. Significant deterioration of neuropsychometric function was defined as either a greater than one standard deviation (SD) postoperative decrease in group performance on a single neuropsychometric test for the group rate method or as decreased performance in more than two of the eight neuropsychometric scores for any individual patient for the event rate method. ${ }^{15,16} \mathrm{We}$ defined cerebral dysfunction as any new abnormality on the neurologic examination, exacerbation of a preexisting neurologic deficit, or significant deterioration in neuropsychometric function at the time of follow-up examination.

For the operation, all patients were premedicated with oral diazepam $(0.1$ to $0.15 \mathrm{mg} / \mathrm{kg})$. Standard monitors including the electrocardiogram, pulse oximeter, intraarterial blood pressure catheter, esophageal temperature probe, and capnometer were applied. General anesthesia was induced with intravenous fentanyl ( 2 to $5 \mu \mathrm{g} / \mathrm{kg}$ ), midazolam ( 0.03 to $0.05 \mathrm{mg} / \mathrm{kg}$ ), and thiopental (3 to 5 $\mathrm{mg} / \mathrm{kg}$ ). Intubation was facilitated by either succinylcholine $(1.5 \mathrm{mg} / \mathrm{kg})$ or vecuronium $(0.1 \mathrm{mg} / \mathrm{kg})$. Anesthesia was maintained with a balanced technique consisting of a continuous fentanyl infusion ( 1 to $2 \mu \mathrm{g} / \mathrm{kg}$ per hour) and nitrous oxide in oxygen supplemented with isoflurane ( $0.2 \%$ to $0.5 \%$ exhaled). Intermittent doses of vecuronium were given for maintenance of neuromuscular blockade. In four patients, vasoactive drugs including either phenylephrine (patients 2, 4, and 9) or ephedrine (patient 6) were administered by intermittent bolus to maintain hemodynamic stability. Surgical techniques for ICD installation are described in detail elsewhere. ${ }^{17}$ In brief, the ICD generator was installed or replaced via a left subcostal incision. In the patients undergoing initial ICD implantation, the defibrillator lead was placed via a left anterior minithoracotomy. In patients undergoing thoracotomy, a lumbar epidural catheter was placed before anesthetic induction, and during surgical closure a bolus of epidural fentanyl $(100$ to $200 \mu \mathrm{g}$ ) was given to these patients for postoperative pain management. All patients were extubated at the conclusion of the operation.

Intraoperative ICD testing was performed after ICD lead insertion. Ventricular arrhythmias were induced by programmed electrical stimulation. Approximately 7 to 8 seconds after VT, VFL, or VF was induced, a 20-joule pulse was given from an external cardioverter-defibrillator. If successful, the lower safety limit for defibrillation was established by incremental 5-joule decreases in the delivered energy level during subsequent arrests. If defibrillation was not successful, an internal "rescue" shock of 40 joules was administered, followed by 400 -joule transthoracic shocks until baseline cardiac rhythm was achieved. The lead configuration was then revised and threshold testing again carried out until satisfactory lead placement was accomplished. The lower safety threshold for defibrillation having been established with the external cardioverter-defibrillator, each ICD was programmed and tested before surgical closure. Circulatory arrest, defined by the absence of a pulsatile arterial waveform, occurred in each case of VF or VFL. Episodes of VT, in which a pulsatile arterial waveform was present, were excluded from analysis, inasmuch as the timing and degree of cerebral hypoperfusion could not be easily delineated. The duration of arrest was established as the interval 


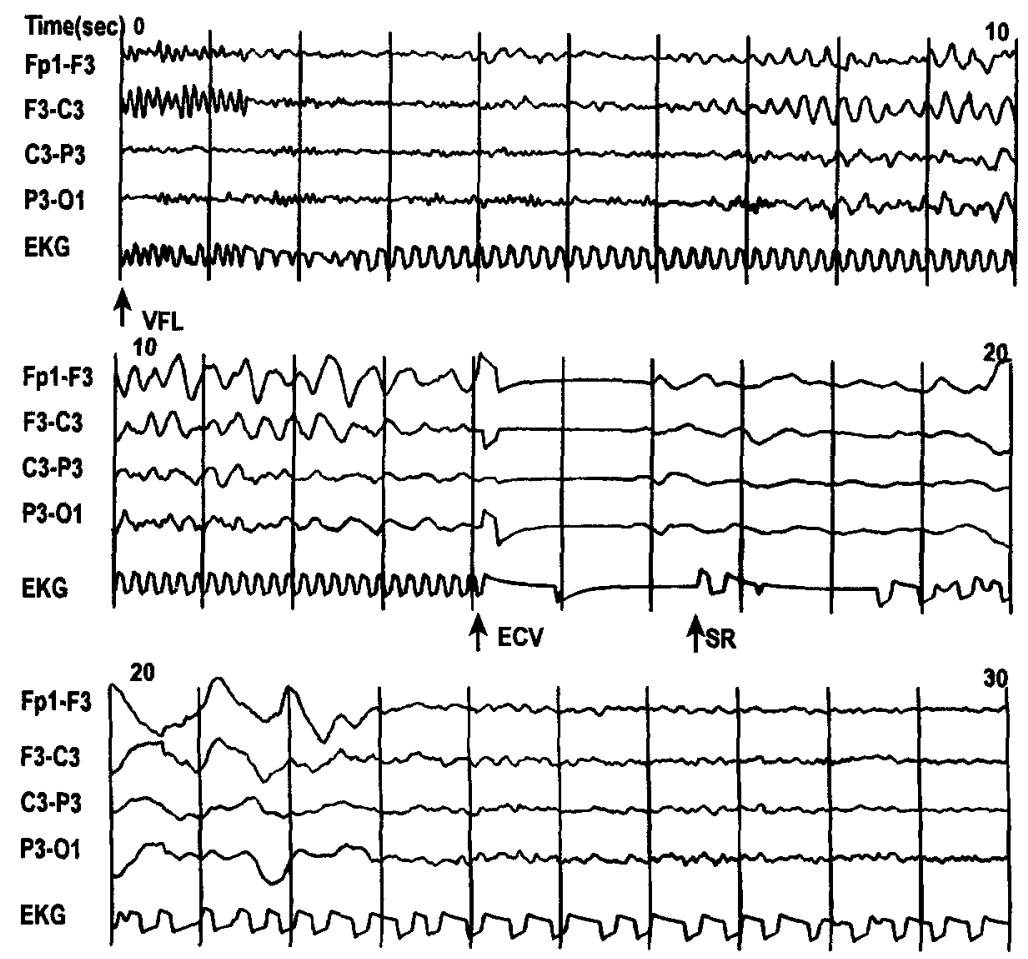

Fig. 1. Four channels of EEG and electrocardiogram ( $E K G)$ recorded during pulseless ventricular flutter (VFL) at a rate of approximately 360 beats/min, electrocardioversion $(E C V)$, and return of sinus rhythm (SR). Vertical lines represent 1-second intervals. Abrupt onset of high-amplitude theta is seen 7 seconds after the onset of VFL. Subsequently, there is progressive slowing and, by 13 seconds, voltage attenuation. EEG recovery is characterized by low-amplitude slow frequency activity signal with subsequent progressive increases in frequency, amplitude, and complexity.

between the onset of VF or VFL and the time that pulsatile arterial blood pressure returned.

The EEG was recorded throughout the procedure, beginning before induction of anesthesia. Scalp electrodes were applied according to the International 10-20 System by means of an electrode embedded nylon cap (ElectroCap International, Eaton, Ohio). Electrode impedances were maintained at less than 5000 ohms throughout the recording. High- and low-pass filters were set at $0.53 \mathrm{~Hz}$ and $70 \mathrm{~Hz}$, respectively. Nineteen channels of EEG data were recorded digitally at 128 samples per second per channel and stored on digital media. The arterial blood pressure waveform, electrocardiogram, and esophageal temperature were also recorded.

The EEG recorded during the arrests was analyzed off-line. A board-certified electroencephalographer (R.G.E.) examined the raw recording and determined the time at which a major change, defined as any visually detectable decrease in fast activity, increase in slow activity, or attenuation of voltage, occurred. To detect cumulative electrophysiologic effect, we compared the interval between the arrest onset and the appearance of raw EEG change in patients who had EEG changes during multiple arrests. This interval was sequentially plotted to detect any downward trend during later arrests. In addition, a 5-minute segment of raw EEG recorded during stable anesthesia at least 5 minutes but not more than 15 minutes after the last arrest was visually compared with a 5-minute segment of EEG recorded before ICD testing for evidence of cerebral ischemia. Fig. 1 illustrates the raw EEG changes observed during a typical arrest and cardioversion.

Automated techniques for interpreting EEG, such as power spectral analysis, have been proposed for intraoperative use because of their relative ease of application, simplicity and clarity of display, and lack of need for frequent on-line adjustment. ${ }^{18,19}$ A power spectral analysis program (Rhythm, Stellate systems, Montreal, Quebec, Canada) was used to process 4-second segments (epochs) of EEG from two channels recording electrical activity generated in the cerebral cortex of the left hemisphere (Fp1-F3 and C3-P3). This program performs a Fourier analysis of digitized EEG to calculate EEG power in the four conventionally defined frequency bands, delta $(0.5$ to $3.75 \mathrm{~Hz})$, theta $(4.0$ to $7.75 \mathrm{~Hz})$, alpha ( 8.0 to 12.75 $\mathrm{Hz}$ ), and beta $(13.0$ to $20.25 \mathrm{~Hz})$. To emphasize the increases in slow activity and decreases in fast activity that were likely to occur with cerebral ischemia, we calculated the ratio (DT/AB) of power in the lowfrequency bands (delta and theta) to power in the high-frequency bands (alpha and beta) and plotted it as a function of time. Examples of the processed EEG 

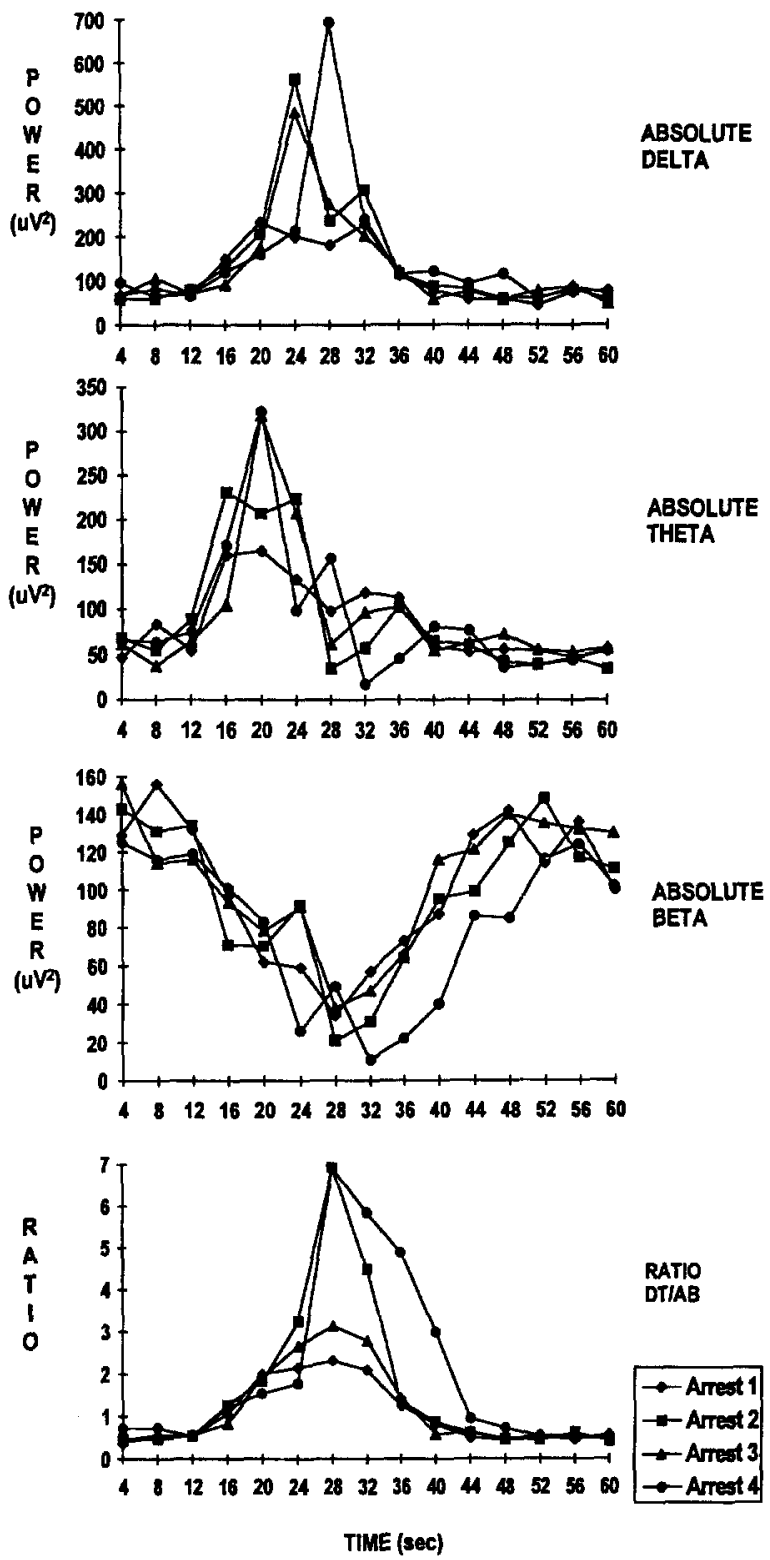

Fig. 2. EEG power $\left(\mu V^{2}\right)$ for the delta, theta, and beta frequency bands and the ratio of low frequency to high frequency power (DT/AB) plotted versus time for the first four arrests in patient 7 . Although prominent increases in power are seen in the DT/AB, delta, and theta bands, a significant decrease in power is shown in the beta band.

results are illustrated in Fig. 2, which depicts the first four arrests in patient 7 .

A modification of Page's cumulative sum (cusum) procedure ${ }^{20,21}$ was used to analyze the processed EEG. This is a statistical method for detection of the occurrence and timing of changes from a preestablished mean in timeseries data. We defined this baseline mean as the average of DT/AB for the two 4-second epochs preceding each episode of circulatory arrest. The cusum value is the sum of successive differences between this baseline and $D T / A B$ for each epoch. When the cusum exceeds a predefined critical value, a change is said to have occurred. The time of change was designated as the instant when the cusum value exceeded 1 for any arrest in which the cusum was eventually greater than 5 . These criteria for defining the presence and timing of processed EEG change were selected empirically to limit both false-positive and falsenegative interpretations, compared with the visually analyzed raw EEG.

Follow-up neurologic and neuropsychometric evaluations were performed on separate occasions between postoperative days 2 and 5 . Patients were fully awake and had not taken narcotic analgesics for a minimum of 4 hours before the examination. No patient had had either postoperative episodes of hypotension or ICD shocks before either follow-up evaluation.

\section{Results}

Neurologic outcome was assessed in eight of the nine patients (patient 2 declined follow-up). Postoperatively, no patient had a new neurologic deficit. Neurologic abnormalities were unchanged in the two patients (patients 6 and 8) who had preoperative neurologic deficits (Table II). No significant deterioration was found either in the group score for any neuropsychometric test according to group rate analysis or in any patient's overall postoperative neuropsychometric performance according to event rate comparisons (Table II).

Fifty circulatory arrests in nine patients were analyzed (see Table I). In 13 arrests occurring in five patients (patients 1, 2, 4, 8, and 9), VFL alone or alternating with VF was observed. In the remaining 37 arrests, VF alone was identified. Each patient's end tidal carbon dioxide values and esophageal temperatures remained stable (range for all patients 28 to $33 \mathrm{~mm} \mathrm{Hg}$ and $34.7^{\circ}$ to $36.1^{\circ} \mathrm{C}$, respectively) during ICD testing. Mean arrest duration was 13.6 seconds (range 5.4 to 31.2 seconds, $\mathrm{SD} \pm 6.4$ seconds).

Alteration of the raw EEG was observed in 30 of the 50 circulatory arrests. Overall, the mean interval between arrest onset and this change was $7.5 \mathrm{sec}-$ onds ( $\mathrm{SD} \pm 1.8$ seconds). No significant difference was found between this interval for the eight episodes of VFL associated with EEG change (7.5 \pm 1.9 seconds) and the $22 \mathrm{VF}$ episodes with EEG alterations ( $7.5 \pm 1.8$ seconds). The initial raw EEG changes were attenuation of fast (alpha and beta) frequency activity $(60 \%, 18 / 30)$, abrupt onset of high-amplitude delta or theta activity $(33 \%, 10 / 30)$, or voltage attenuation $(7 \%, 2 / 30)$, alone or in combination. No significant difference was noted be- 
tween the means of the lowest recorded blood pressure for arrests that did not demonstrate EEG change $(36.7 \pm 6.2)$ and those that did show EEG change ( $33.5 \mathrm{~mm} \mathrm{Hg}, \mathrm{SD} \pm 5.2 \mathrm{~mm} \mathrm{Hg}$ ). The mean duration (8.1 seconds, SD \pm 2.0 seconds) of 20 arrests without EEG change was significantly shorter than the mean duration ( 17.3 seconds, SD \pm 5.5 seconds) of 30 arrests with EEG change $(p<$ 0.01 ). EEG changes were noted in only 3 of 20 arrests of less than 10 seconds in length, whereas 27 of the 30 arrests that were of more than 10 seconds' duration showed alteration in the EEG $(p<0.01)$. Furthermore, EEG change was observed in all of the 19 arrests lasting more than 15 seconds.

In the three patients $(1,6$, and 7$)$ in whom multiple arrests were associated with EEG change, no downward trend in the interval between arrest onset and alteration of the EEG was apparent. The baseline EEGs demonstrated anesthesia-dependent patterns, consisting of fast frequency superimposed on rhythmic slower frequency activity. Visual comparison of the 5-minute prearrest and postarrest EEG segments revealed no abnormal increase in slow activity, decrease in fast activity, or voltage attenuation that would reflect cerebral ischemia in the postarrest recordings.

The cusum procedure correctly identified EEG changes in 26 arrests. It failed to detect change in four arrests in which deterioration of the EEG was identified by visual analysis, and it detected change in the absence of corresponding alteration by visual analysis in six cases (see Table I). Thus, compared with conventional assessment of the EEG, interpretation of the processed EEG by means of the $\mathrm{DT} / \mathrm{AB}$ descriptor and the cusum procedure has positive and negative predictive values of $81 \%$ and $78 \%$, respectively, with a sensitivity of $87 \%$ and a specificity of $70 \%$. Designating the time of change as the time at which the cusum value first exceeded 1 , the cusum procedure identified EEG change at the same time or earlier than visual analysis in 15 arrests and later in 11 cases.

An example of a false-positive detection, reflecting an inherent limitation of power spectral based techniques of automated EEG analysis, is illustrated in Figs. 3 and 4. In Fig. 3, the raw EEG recording from patient 8 during periods of VT and VFL is contaminated by artifact resulting from cardiac electrical activity detected by the scalp electrodes. In Fig. 4, two distinct DT/AB peaks corresponding to the respective periods of VT and VFL are seen in the plot of the processed EEG as a function of time for the
Table II. Results of neurologic examination and neuropsychometric tests

\begin{tabular}{|c|c|c|c|}
\hline \multirow{2}{*}{$\begin{array}{c}\text { Patient } \\
\text { No. }\end{array}$} & \multicolumn{2}{|c|}{$\begin{array}{l}\text { Neurologic } \\
\text { examination }\end{array}$} & \multirow{2}{*}{$\begin{array}{l}\text { NP tests with } \\
>25 \% \text { decline } \\
\text { in postop. } \\
\text { performance }\end{array}$} \\
\hline & Preop. & Postop. & \\
\hline 1 & Normal & Normal & None \\
\hline 3 & Normal & Normal & None \\
\hline 4 & Normal & Normal & None \\
\hline 5 & Normal & Normal & TB, RT-ND \\
\hline 6 & $\mathrm{R}$ hemi & R hemi & GPB-DO \\
\hline 7 & Normal & Normal & None \\
\hline 8 & L-PM & L-PM & None \\
\hline 9 & Normal & Normal & None \\
\hline
\end{tabular}

$R$ hemi, Right hemiparesis; $L-P M$, left palmomental reflex; $T B$, HalsteadReitan Trails B; $R T-N D$, repetitive tapping of nondominant hand; $G P B$ $D O$, grooved peg board, dominant hand.

C3-P3 channel. Although this artifact is detected as a significant event by the cusum procedure at 16 seconds after the onset of VT, the actual EEG change does not occur until nearly 16 seconds later.

\section{Discussion}

In experimental animals, neuronal injury may be produced by transient cerebral ischemia caused by hemorrhagic hypotension, ${ }^{6}$ carotid occlusion, ${ }^{7-9,22}$ and cardiac arrest. ${ }^{23,24}$ Cumulative histopathologic changes may result from brief repeated 2- to 5 -minute episodes of cerebral ischemia. ${ }^{6-9}$ It has been suggested that ICD testing, entailing repeated cardiac arrests, might result in cumulative EEG changes. ${ }^{4}$ We examined the interval between the onset of circulatory arrest and the appearance of EEG change, hypothesizing that the latter might be decreased after repeated arrests. Although the EEG recorded during the arrests clearly demonstrated time-dependent change, in the three patients who had EEG changes during multiple arrests, the number of preceding arrests did not appear to affect the time to onset of EEG change in subsequent arrests. In addition, comparison of prearrest and postarrest EEG recordings provided no evidence of deterioration in any patient.

Numerous EEG descriptors have been investigated to determine their ability to identify intraoperative cerebral ischemia and predict postoperative neurologic outcome. ${ }^{25}$ For example, persistent ${ }^{26}$ and cumulative ${ }^{27}$ decreases in the "spectral edge," a measure of high-frequency EEG activity, have been associated with postoperative neurologic complications after carotid endarterectomy. The EEG changes associated with cerebral ischemia during 


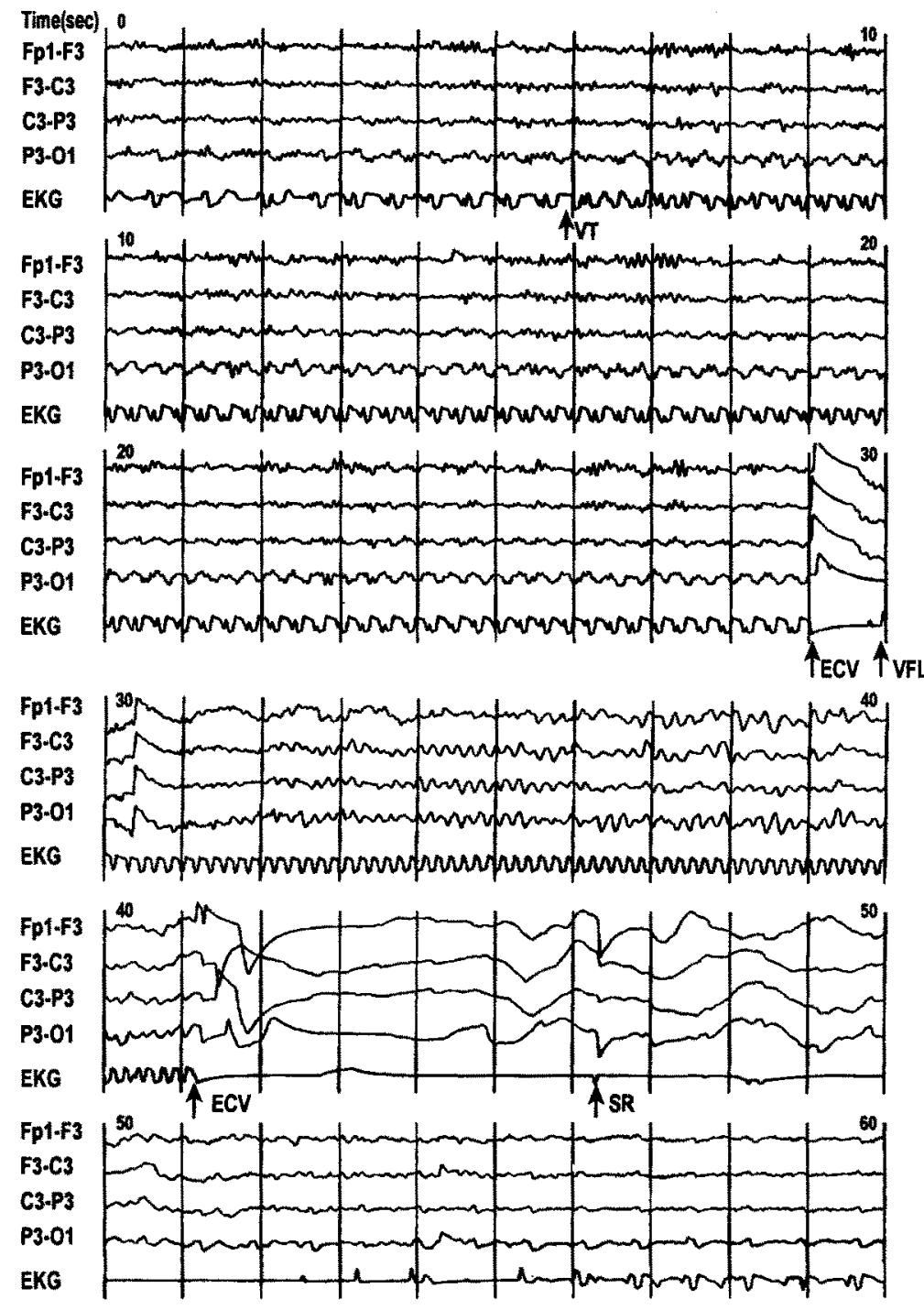

Fig. 3. Four bipolar channels of EEG and electrocardiogram (EKG) recorded during ventricular tachycardia (VT) at a rate of approximately 180 beats/min, electrocardioversion $(E C V)$, ventricular flutter $(V F L)$ at a rate of approximately 360 beats/min, and return of sinus rhythm $(S R)$ in patient 8 .

iatrogenic cerebral hypoperfusion, ${ }^{28-30}$ carotid endarterectomy, ${ }^{26,31,32}$ and unexpected cardiac arrest $^{33-35}$ have been described. The classic pattern of ischemic EEG alterations is characterized by an initial decrease in fast frequency activity with a subsequent progressive increase in slow wave activity eventually leading to isoelectricity. ${ }^{28,30}$ Voltage attenuation alone or in combination with EEG slowing, ${ }^{1-3,31,33}$ decreased spectral edge, ${ }^{2,26,35}$ large-amplitude theta waves, ${ }^{1}{ }^{1}$ decreased delta activity, ${ }^{1}$ and appearance of a burst suppression EEG pattern ${ }^{36}$ are also observed.

The implantation and testing of ICD devices provides an opportunity to examine the EEG changes associated with global cerebral hypoperfusion in man. ${ }^{1-4}$ The range of arrest duration in our study is somewhat less than the 15 to 126 seconds of ventricular arrhythmias reported in patients undergoing postoperative ICD testing ${ }^{3}$ and the 8 to 67 seconds of hypotension reported in other patients undergoing intraoperative ICD testing. ${ }^{5}$ However, the mean interval of 7.5 seconds between the onset of arrest and the appearance of changes in the raw EEG in our study is similar to the 10.2 seconds reported in other patients undergoing ICD placement $^{\mathrm{l}}$ and to the occurrence, at 6.8 seconds, of 


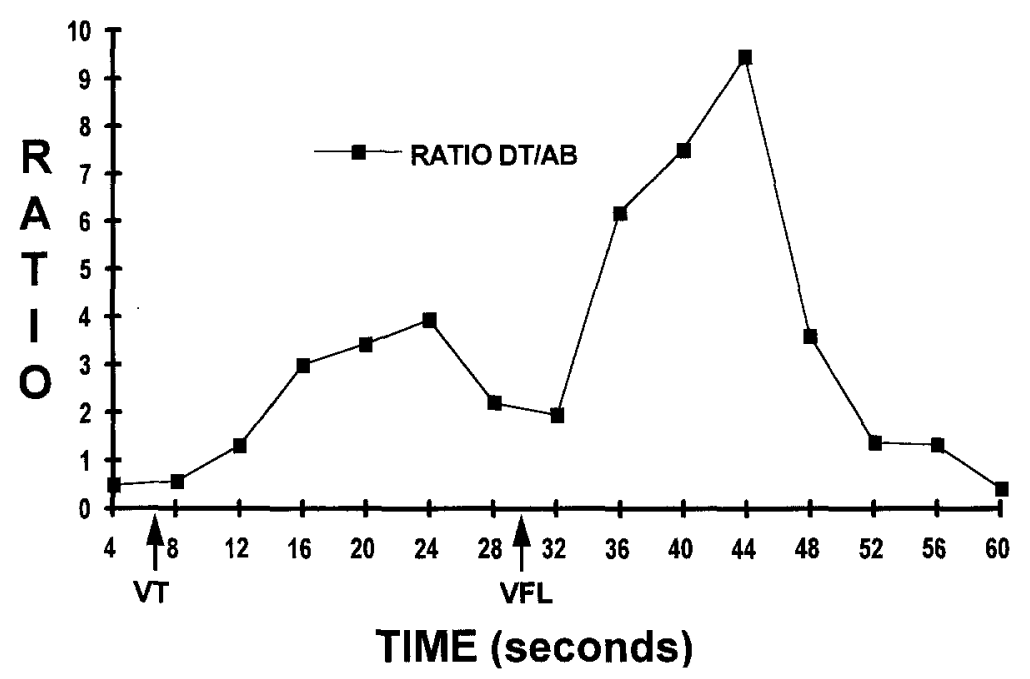

Fig. 4. The ratio of low frequency to high frequency power (DT/AB) for the C3-P3 channel plotted versus time during periods of ventricular tachycardia $(V T)$ and ventricular flutter (VFL) corresponding to raw EEG data presented in Fig. 3.

unconsciousness and large-amplitude delta activity in human beings undergoing experimental arrest of cerebral circulation. $^{28}$ These small differences may reflect anesthetic effects, the number of FEG channels analyzed, or simply qualitative variation in interobserver EEG interpretation.

Consistent with the guidelines of the American Encephalographic Society, ${ }^{37}$ the raw EEG recordings contained an electrocardiographic trace. Although this introduces a potential source of observer bias because the EEG is interpreted without blinding to cardiac events, artifact from cardiac electrical contamination of the EEG may contribute to erroneous interpretation of the EEG (e.g., Fig. 3). Inasmuch as others have observed changes in the raw and processed EEG during $80 \%$ to $90 \%$ of arrests $^{1,4,5}$ and EEG changes were evident in only $60 \%$ of arrests in our study, it is possible that more restricted criteria for designating change were used in the visual inspection of our EEGs. Nonetheless, we consider this possibility to be unlikely because we observed EEG alterations slightly earlier during arrests than did other investigators. The age range of patients in our study is similar to those in others in which the EEG was examined during ICD insertion. ${ }^{1,3}$ However, the mean age of 47 years in our study is slightly younger than the means of 58 to 62 years reported in other investigations. ${ }^{1,4,5}$ Nonetheless, we do not believe that this difference in mean age accounts for any disparity in the EEG results. Rather, we speculate that the generally shorter duration of arrests in our study accounts for the less frequent occurrence of ischemic EEG changes.

During ICD testing, alteration in the processed EEG is ordinarily seen later ${ }^{4,5}$ and less frequently ${ }^{2}$ than in corresponding segments of visually interpreted raw EEG. Our results suggest that using the ratio of low frequency to high frequency power (DT/AB) and the cusum procedure of continuous data inspection may be an effective scheme for automated detection of intraoperative cerebral ischemia. However, as illustrated in Figs. 3 and 4, automated techniques of EEG interpretation are most reasonably applied as adjuncts to conventional visual inspection of the EEG, because they cannot reliably distinguish many forms of artifactual contamination from cerebral electrical activity. ${ }^{38}$

Perioperative neuropsychometric testing has been used to establish subtle evidence of "cerebral dysfunction" in patients who have had cardiac surgery ${ }^{16,39-42}$ compared with control groups having nonsurgical cardiac disease ${ }^{42}$ or vascular surgery. ${ }^{16,42}$ In our study, no significant deterioration in postoperative neuropsychometric function was detected by either group rate or event rate analysis of the neuropsychometric scores. The $25 \%$ incidence of mild deterioration in one or two neuropsychometric tests in our patients is similar to that reported in control populations, including patients who have had vascular surgery $(31 \% \text { to } 36 \%)^{16,42}$ and those with nonsurgical cardiac disease (20\%). ${ }^{42}$ Age and extracoronary vascular disease have been 
associated with poor neurologic outcome after cardiac operations. ${ }^{43}$ It is possible that elderly patients and those with cerebrovascular disease would similarly fare worse after multiple cardiac arrests for ICD implantation. However, because our study was not designed to examine these effects, elucidation of the specific roles of age and preexisting vascular disease on neurologic outcome in patients having an ICD awaits further investigation.

We have found no neurophysiologic evidence for cumulative cerebral injury from brief repeated episodes of circulatory arrest during ICD implantation. In addition, we have found no significant change in postoperative neurologic status as determined by standard neurologic and neuropsychometric testing. Our findings suggest that ICD insertion and testing is not associated with permanent neurologic injury.

We thank Eugene Pantuck, MD, for his assistance in editing this manuscript and Karen Buck, MS, for her assistance with the statistical analysis.

\section{REFERENCES}

1. Clute HL, Levy WJ. Electroencephalographic changes during brief cardiac arrest in humans. Anesthesiology 1990;73:821-5.

2. Konstadt S, Blakeman B, Wilbur D, Warf P, Stull C, Rao T. The effects of global normothermic hypoperfusion on processed EEG in patients. Anesth Analg 1990;70:S213.

3. Aminoff MJ, Scheinman MM, Griffing JC, Herre JM. Electrocerebral accompaniments of syncope associated with malignant ventricular arrhythmias. Ann Intern Med 1988;108:791-6.

4. Singer I, van der Laken J, Edmonds HL Jr, et al. Is defibrillation testing safe? PACE 1991;11:1899-904.

5. Dorman BH, Conroy JM, Baker JD III, Kratz JM, Leman RB. Cerebral monitoring during implantation of automatic internal cardiac defibrillators. South Med J 1993;86:533-6.

6. Yamauchi Y, Kato H, Kogure K. Hippocampal damage following repeated brief hypotensive episodes in the rat. J Cereb Blood Flow Metab 1991;11:974-8.

7. Kato H, Kogure K, Nakano S. Neuronal damage following repeated brief ischemia in the gerbil. Brain Res 1989;479:366-70.

8. Kato $\mathrm{H}$, Kogure $\mathrm{K}$. Neuronal damage following nonlethal but repeated cerebral ischemia in the gerbil. Acta Neuropathol 1990;79:494-500.

9. Tomida S, Nowak TS Jr, Vass K, Lohr JM, Klatzo I. Experimental model for repetitive ischemic attacks in the gerbil: the cumulative effect of repeated ischemic insults. J Cereb Blood Flow Metab 1987;7:773-82.

10. Reitan RM. Validity of the Trail Making Test as an indication of organic brain damage. Percept Mot Skills 1958;8:271-6.

11. Lezak MD. Executive functions and motor performance. In: Neuropsychological assessment. 2nd ed. New York: Oxford University Press, 1983:507-32.

12. Klove H. Clinical neuropsychology. Med Clin North Am 1963;47:1647-58.

13. Buschke H, Fuld PA. Evaluating storage, retention, and retrieval in disordered memory and learning. Neurology 1974;24:1019-25.

14. Horton AM Jr, Slone DG, Shapiro S. Neuropsychometric correlates of the Mini-Mental State Examination: preliminary data. Percept Mot Skills 1987;65: 64-6.

15. Stump D, Newman S, Troost B, Prough D, Furberg C. Neuropsychological deficits after cardiac surgery. Anesth Analg 1991;72:S282.

16. Shaw PJ, Bates D, Cartlidge NEF, et al. Neurologic and neuropsychological morbidity following major surgery: comparison of coronary artery bypass and peripheral vascular surgery. Stroke 1987;18:700-7.

17. Spotnitz HM. Surgical approaches to ICD insertion. In: Spotnitz HM, ed. Research frontiers in implantable defibrillator surgery. 1st ed. Austin: RG Landes Company, 1992;23-34.

18. Rampil IJ. What every neuroanesthesiologist should know about electroencephalograms and computerized monitors. Anesth Clin North Am 1992;10:683718.

19. Levy WJ, Shapiro HM, Maruchak G, Meathe E. Automated EEG processing for intraoperative monitoring: a comparison of techniques. Anesthesiology 1980;53:223-36.

20. Page ES. Continuous inspection schemes. Biometrika 1954;41:100-15.

21. Weatherall JAC, Haskey JC. Surveillance of malformations. Br Med Bull 1976;32:39-44.

22. Araki $T$, Kato $H$, Kogure $K$. Selective neuronal vulnerability following transient cerebral ischemia in the gerbil: distribution and time course. Acta Neurol Scand 1989;80:548-53.

23. Blomqvist $\mathrm{P}$, Wieloch $\mathrm{T}$. Ischemic brain damage in rats following cardiac arrest using a long-term recovery model. J Cereb Blood Flow Metab 1985;5:420-31.

24. Anstadt MP, Stonnington MJ, Tedder M, et al. Pulsatile reperfusion after cardiac arrest improves neurologic outcome. Ann Surg 1991;214:478-88.

25. Young WL, Moberg RS, Ornstein E, et al. Electroencephalographic monitoring for ischemia during carotid endarterectomy: visual versus computer analysis. J Clin Monit 1988;4:78-85.

26. Rampil IJ, Holzer JA, Quest DO, Rosenbaum SH, Correll JW. Prognostic value of computerized EEG analysis during carotid endarterectomy. Anesth Analg 1983;62:186-92.

27. Tempelhoff R, Modica PA, Grubb RL, Rich KM, 
Holtmann B. Selective shunting during carotid endarterectomy based on two-channel computerized electroencephalographic/compressed spectral array analysis. Neurosurgery 1989;24:339-44.

28. Rossen R, Kabat H, Anderson JP. Acute arrest of cerebral circulation in man. Archiv Neurol Psychiatry 1943;50:510-28.

29. Forster FM, Roseman E, Gibbs FA. Electroencephalogram accompanying hyperactive carotid sinus reflex and orthostatic syncope. Archiv Neurol Psychiatry 1942;48:957-67.

30. Sugar O, Gerard RW. Anoxia and brain potentials. J Neurophysiol 1938;1:558-72.

31. Chiappa KH, Burke SR, Young RR. Results of electroencephalographic monitoring during $367 \mathrm{ca}-$ rotid endarterectomies: use of a dedicated minicomputer. Stroke 1979;10:381-8.

32. Sundt TMJ, Sharbrough FW, Piepgras DG, Kearns TP, Messick JMJ, O'Fallon WM. Correlation of cerebral blood flow and electroencephalographic changes during carotid endarterectomy with results of surgery and hemodynamics of cerebral ischemia. Mayo Clin Proc 1981;56:533-43.

33. Losasso TJ, Muzzi DA, Meyer FB, Sharbrough FW. Electroencephalographic monitoring of cerebral function during asystole and successful cardiopulmonary resuscitation. Anesth Analg 1992;75:1021-4.

34. Moss J, Rockoff M. EEG monitoring during cardiac arrest and resuscitation. JAMA 1980;244:2750-1.

35. Young WL, Ornstein E. Compressed spectral array
EEG monitoring during cardiac arrest and resuscitation. Anesthesiology 1985;62:535-8.

36. Brierley JB, Prior PF, Calverley J, Brown AW. Profound hypoxia in Papio anubis and Macaca mulattaphysiological and neuropathological effects. J Neurol Sci 1978;37:1-29.

37. AEEGS. Guideline one: Minimum technical requirements for performing clinical electroencephalography. J Clin Neurophysiol 1994;11:2-5.

38. AEEGS. American Electroencephalographic Society statement on the clinical use of quantitative EEG. J Clin Neurophysiol 1987;4:75.

39. Sotaniemi KA, Mononen H, Hokkanen TE. Longterm cerebral outcome after open-heart surgery. Stroke 1986;17:410-6.

40. Savageau JA, Stanton B-A, Jenkins CD, Klein MD. Neuropsychological dysfunction following elective cardiac operation I. Early assessment. J THORAC CARDIOVASC SuRg 1982;84:585-94.

41. Savageau JA, Stanton B-A, Jenkins CD, Frater RWM. Neuropsychological dysfunction following elective cardiac operation II. A six-month reassessment. J Thorac Cardiovasc Surg 1982;84:595-600.

42. Hammeke TA, Hastings JE. Neuropsychologic alterations after cardiac operation. J THORAC CARDIOVASC SURG 1988;96:326-31.

43. Shaw PJ, Bates D, Cartlidge NEF, et al. An analysis of factors predisposing to neurological injury in patients undergoing coronary bypass operations. Q J Med 1989;72:633-46. 